\title{
ARAUJO, Patrício Carneiro. 2017. Entre Ataques e Atabaques: intolerância religiosa e racismo nas escolas. São Paulo: Aché. 300 pp.
}

\author{
KELSON GÉRISON OLIVEIRA CHAVES
}

Entre Ataques e Atabaques é, a um só tempo, um livro sobre racismo, sobre educação e sobre intolerância religiosa no Brasil. De tal modo, a primeira coisa que se deve dizer acerca deste trabalho é que, com ele, o pesquisador Patrício Carneiro Araújo conseguiu oferecer uma discussão que não se restringe ao afunilamento monográfico, servindo a debates mais amplos.

Construído na interface entre a tese de doutorado do autor e a pesquisa institucional da qual participava, intitulada Racismo e educação: a lei 10.639/2003 na rede pública do Estado de São Paulo, o livro abarca também os motivos que têm dificultado a implementação da lei 10.639/2003 no universo escolar, que estabeleceu a obrigatoriedade do ensino de História e Cultura Africana e Afro-Brasileira no currículo da educação básica, e aponta caminhos para a superação desse problema.

Tomando como campo de pesquisa escolas da rede pública de São Paulo-SP, bem como terreiros de Candomblé e Umbanda situados na mesma cidade, o autor consegue demonstrar a grande incidência de casos de intolerância para com as religióes afro-brasileiras no mundo escolar. Concomitantemente, procura explicar como esse contexto foi construído e como ele representa um obstáculo gigantesco à plena efetivação da lei 10.639/2003.

Sendo, por formação e profissão, um educador, pesquisador, antropólogo e, ao mesmo tempo, iniciado no Candomblé, o autor consegue realizar movimentos analíticos que articulam um olhar "de dento" e um olhar "de fora", o que pode tê-lo ajudado a compreender mais profundamente "as relações entre as religiões afro-brasileiras e a escola, a mídia, a política institucional, as outras religiões e a vida social mais abrangente" (p.24).

Patrício Carneiro Araújo assume em seu texto, prontamente, o fato de vivenciar uma condição dupla: professor na educação básica (da disciplina História) e adepto do Candomblé, condição esta que o caracterizou, nessa pesquisa, como um pesquisador-nativo. A objetividade e franqueza com que coloca isto logo de início, evidenciando as condições de coleta e produção dos dados empíricos e o lugar de onde o pesquisador fala, corroboram para a honestidade acadêmica e científica de seu trabalho. 
É preciso observar também que o autor procurou combinar, diga-se, com muita perspicácia, diferentes técnicas de pesquisa e coleta/produção de dados, indo desde a aplicação de questionários a entrevistas e à observação cotidiana em escolas e também junto a pessoas que tinham ligações com terreiros de Candomblé e de Umbanda e que transitavam entre a comunidade escolar e a comunidade religiosa dos terreiros. Aqui, a posição de pesquisador-nativo foi um elemento facilitador do trânsito de Patrício Carneiro Araújo nos dois ambientes, ampliando suas possibilidades de acesso à informação e ao diálogo etnográfico.

Partindo para o conteúdo do livro, observamos que o fio condutor de todo o texto é tramado em torno de duas teses. A primeira é a de que existe racismo no mundo escolar e de que este fato dificulta sobremaneira a implementação da lei 10.639/2003. A segunda é a de que a intolerância religiosa, presente no mundo escolar, contra seguidores de religiões afro-brasileiras, representa uma forma de racismo. Estes atos de intolerância, que acabam se configurando como uma forma de racismo, são observáveis não só entre alunos, mas também entre professores, gestores e funcionários.

$\mathrm{O}$ autor argumenta que, como a religião é um dos aspectos basilares de qualquer sociedade $\mathrm{e}$ cultura, e como a lei 10.639/2003 torna obrigatório o ensino de História e Cultura Africana e Afro-brasileira, na medida em que as religiões afro-brasileiras são relegadas e suprimidas na escola, é a própria aplicação da lei que fica comprometida, pois as religiões afro-brasileiras são elementos essenciais da História e Cultura Afro-Brasileiras, não sendo viável abordá-la relegando as características e trajetórias de tais religiões.

Isto se dá, nas palavras do autor, devido o racismo institucionalizado e diluído nas escolas, que, repetidamente, manifesta-se por meio de diferentes formas de discriminação e inferiorização de elementos culturais de origem africana no Brasil, sendo que as religióes afro-brasileiras são o objeto predileto dessa depreciação.

Para discorrer sobre essa e outras questões, uma das principais ferramentas analíticas do autor, em termos teóricos, é a Sociologia do Estigma, de Erving Goffman, que compreende que as relações sociais são marcadas e condicionadas por estigmas que determinam a convivência, onde a escola seria um espaço-chave na manifestação e convivência com os diferentes estigmas.

Nessa linha de pensamento, Patrício Carneiro Araújo afirma que "o eu do estudante adepto ou simpatizante das religiões afro-brasileiras constitui" um eu estigmatizado que se vê, na sala de aula e na escola como um todo, sempre silenciado e forçado a negar sua pertença religiosa, visto que "uma identidade social, religiosa e cultural hegemônica dá substrato a relações de rejeição e estigmatização dos seguidores das religiões afro-brasileiras" (p.36).

Até por isso, o pesquisador encontrou nos espaços escolares uma postura silenciada e resguardada de alunos e professores que eram adeptos de religiões afro-brasileiras. Foi o que o levou a decidir direcionar sua interlocução para os terreiros. E, partindo dos terreiros, passou a dialogar mais recorrentemente com aqueles adeptos que vivenciavam esses dois mundos violentamente apartados: o terreiro e a escola.

No decorrer do texto, sempre perseguindo as questões do racismo institucionalizado na escola, da intolerância religiosa e das dificuldades para a aplicação da lei 10.639/2003, o autor constatou que, 
mesmo quando a História e Cultura Afro-brasileira (componentes obrigatórios do currículo) eram trabalhadas em sala de aula, os temas relacionados às religiões afro-brasileiras, via de regra, eram sempre evitados. Temas como artes, danças, culinária africana, entre outros, nem sempre eram problemas. Quando se tratava das religiões de origem afro, contudo, surgiam conflitos provocados por pessoas de pertença religiosa cristã evangélica: alunos, professores e até gestores.

Esse problema seria decorrente do crescimento vertiginoso que as vertentes religiosas cristãs de caráter mais fundamentalista e intolerante, isto é, as igrejas neopentecostais, alcançaram no Brasil nas últimas décadas. Esse crescimento, hoje, adentra e influencia de forma problemática o espaço escolar e as práticas pedagógicas. É o que o autor chamou argutamente de "pentecostalização do magistério" (p.127).

Sobre essa questão, o autor coloca que atualmente a Igreja Católica, com exceção da vertente chamada de Renovação Carismática, adotou uma postura mais moderada e tolerante em relação às religiões africanas e afro-brasileiras, o que não acontecia no passado. Por isso, em sua análise, o autor privilegia atos de intolerância praticados por membros de igrejas evangélicas neopentecostais, mostrando que elas são, de longe, as protagonistas, no Brasil contemporâneo, quando o assunto é intolerância religiosa.

Há de se dizer que o autor não faz conclusões ou conjecturas inconsistentes, apresentando no decorrer de sua investigação e construção argumentativa amplo domínio sobre os estudos mais importantes da área, abrangendo temáticas como o racismo institucional, relações étnico-raciais, história do negro no Brasil, estudos da diáspora, identidade afro-brasileira, princípios norteadores das experiências religiosas católicas, evangélicas e afro-brasileiras, dados e legislação sobre intolerância religiosa, entre outras.

O livro também revisita a história da educação no Brasil, mais especificamente no que diz respeito à relação entre a escola e as populações afrodescendentes. A ideia do autor é a de que "para compreender as relações escolares contemporâneas no Brasil é indispensável revisitar seus primórdios e seu desenvolvimento histórico" (p.50).

Foi por esse caminho, inclusive, que o autor chegou à conclusão de que grande parte dos atos de intolerância religiosa praticados no mundo escolar, por alunos, professores e gestores neopentecostais, são herdeiros e continuadores de uma educação igualmente racista, intolerante e excludente empreendida pela Igreja Católica durante a formação do nosso Estado-nação e de nosso sistema educacional.

Fazendo esse trajeto por nossa história, o autor evidencia como, desde a colonização, os valores civilizatórios europeus e cristãos foram impostos como superiores aos valores e religiosidades de origem afro. Algo que ainda acontece atualmente de maneira mais recorrente do que poderíamos imaginar.

Refletindo, em certo momento, a partir das ideias de Bourdieu sobre os mecanismos de reprodução, pelo universo educacional, da ordem e cultura estabelecidas, o autor discorre sobre a forma como o negro e os elementos culturais de origem africana são tratados na escola, demonstrando a recorrência de práticas e atitudes reveladoras do quanto a escola se prende à disseminação "de valores ligados aos grupos historicamente majoritários, a saber, as classes social e economicamente mais favorecidas e aos valores religiosos e culturais relacionados com o universo cristão" (p.182). 
Diante desse cenário, de crescimento das religiões neopentecostais e de sua infiltração no mundo da educação, Patrício afirma, sem pestanejar, que a escola, de pretensa instituição democrática e libertadora, se transmuta em um lugar de reprodução e difusão de uma corrente religiosa que prega a intolerância como um dever divino de combater "o mal”. A escola passa a ser efetivamente um lugar de silenciamento e opressão dos sujeitos de pertença religiosa afro-brasileira e dos valores culturais contidos nessas vivências. Ou seja, justamente o contrário do que se idealiza no discurso sobre a educação escolar como sendo um veículo de "libertação".

Devemos acrescentar que o autor nos apresenta, em seu trabalho, um enorme catálogo de atos de intolerância religiosa que até transcendem o ambiente da escola, (alunos, gestores e professores), chegando a membros do sistema Judiciário e até a chefes do crime organizado que se converteram a alguma igreja evangélica neopentecostal. E tudo isso não acontece, como prova o autor, por falta de legislação sobre o assunto em nosso país. Muito pelo contrário. À margem e revelia da lei, os repetidos e cotidianos casos de intolerância religiosa desafiam a própria legislação existente e sua capacidade de inibir esse tipo de conduta.

Em termos de legislação, a intolerância religiosa é caracterizada no Brasil como crime de repercussão internacional e também crime contra a humanidade, visto que o Brasil se submete, como signatário, ao Tribunal Internacional de Direitos Humanos que, segundo sua jurisdição, considera que crimes por motivação religiosa são crimes contra à humanidade.

Entretanto, a existência dessa legislação não conseguiu impedir o aumento dos casos de intolerância religiosa para com os sujeitos pertencentes às religiões afro-brasileiras. Para o autor, em grande medida, isso ocorre porque o tratamento jurídico não está à altura da gravidade da situação, não cumprindo a letra da lei. Logo, o aumento dos casos de intolerância religiosa e a impunidade reinante são resultados não de um vácuo jurídico, mas sim de relações de poder desiguais que se espraiam nas diferentes instituições sociais.

Embora o valor do conteúdo de um livro jamais possa ser medido por seu alcance de vendas, o sucesso editorial que o livro tem alcançado, desde seu recente lançamento, na área de Antropologia, bem como sua ótima recepção entre educadores, membros de religiões afro-brasileiras e demais cidadãos interessados no assunto, sua primeira edição, segundo dados da própria editora, esgotando-se em poucos meses após o lançamento e o autor tendo sido convidado a falar sobre sua pesquisa em inúmeros eventos recentes, é um demonstrativo do quanto sua temática é imperativa e seu valor reconhecido no contexto do Brasil contemporâneo.

Se se poderia fazer uma crítica, ao analisar o todo da pesquisa e de sua efetivação em livro, seria acerca da apresentação da etnografia. $\mathrm{O}$ autor demonstra ter coletado muito mais material, entrevistas e observações, em terreiros e espaços escolares, do que o que foi possível de ser apresentado, nos deixando, assim, com o desejo de ler, ver e ouvir mais sobre ele. É possível que tenhamos em breve novas publicações do autor sobre o assunto, explorando esse material etnográfico ainda inédito e tão precioso.

Num momento em que o país assiste a retrocessos civis e políticos em vários âmbitos da sociedade, quando os direitos humanos estão sendo frontalmente atingidos, inclusive no meio artístico e 
cultural, o livro Entre Ataques e Atabaques: intolerância religiosa e racismo nas escolas surge como uma voz que enfrenta essa corrente, se tornando uma leitura necessária a todos aqueles que desejam um país mais justo e solidário.

Kelson Gérison Oliveira Chaves é doutor em Ciências Sociaispela Universidade Federal do Rio Grande do Norte (UFRN) e pós-doutorando PNDP/CAPES no mestrado interdisciplinar em Ciências Sociais e Humanas da Universidade Estadual do Rio Grande do Norte (UERN).

RECEBIDO: $22 / 04 / 2018$

APROVADO: $10 / 09 / 2018$ 
212 CAMpos V.19 N.1 jan.jun.2018 